\title{
My patient has left me money in their will. Can I accept?
}

Being left a legacy by a patient can often lead to an ethical dilemma. Abi Rimmer gathers advice from three experts

\section{Abi Rimmer}

The BMJ

\section{Consider how it could be perceived}

Richenda Tisdale, medicolegal consultant at Medical Protection, says, "General Medical Council guidance says that you can accept unsolicited gifts from patients as long as this 'does not affect, or appear to affect, the way you prescribe for, advise, treat, refer, or commission services for patients and you have not used your influence to pressurise or persuade patients or their relatives.'

"The GMC also says, however, that you should consider the potential damage to patients' trust in you and the profession if you accept these gifts. You should also be mindful of the case of a psychiatrist who faced erasure from the medical register in 2011 as a result of accepting a legacy of over $£ 1 \mathrm{~m}(€ 1.1 \mathrm{~m}$; $\$ 1.3 \mathrm{~m}$ ) from a patient to whom he had prescribed excessive doses of benzodiazepines.

"If a patient mentions that they plan to leave you money in their will it might be prudent to explain that, while the gesture is generous, it isn't necessary and could pose difficulties. Instead, you might suggest a donation to a charity of their choice.

"If you receive an unexpected and unsolicited modest amount, it would be a matter for your own discretion as to whether you choose to accept. You should disclose this to your colleagues or employer in accordance with their policy on gifts. You should also bear in mind that a will is a public record and you may face scrutiny from relatives of the deceased, your patients, or the GMC. Your medical defence organisation can offer specific advice."

\section{Be wary of conflicts of interest}

Victoria Moore, standards policy officer at the GMC, says, "Doctors provide an invaluable service every day, supporting us through some of life's most challenging moments. Most patients are deeply grateful and occasionally one might seek to express this through an unsolicited gift or leaving money in their will.

"It may be perfectly reasonable for a doctor to accept a small token of appreciation, but accepting a large sum of money is far more contentious.

"However generous the amount, doctors must be mindful of our guidance on conflicts of interest and consider how accepting the gift might be seen by others, and whether it might affect patient and public trust. Doctors should consider how the public might see their decision, and how this might impact their professional relationships.

"Doctors must never encourage patients to give, lend, or bequeath money or gifts. Nor should they try to persuade them to make donations to other people or organisations. The acceptance of a gift mustn't affect, or be seen to affect, the way a doctor treats or prescribes for a patient.

"It's a matter of professional discretion, and doctors must be prepared to explain their decision. Ultimately, gifts should be refused if they could be seen as an abuse of trust.

"For most doctors, bequests will come as a surprise and, understandably, this news may result in some uncertainty and confusion. We recommend doctors get in touch with their medical defence organisation, as they are equipped to provide legal advice and support."

\section{Ask your colleagues}

Kathryn Leask, medicolegal adviser at Medical Defence Union, says, "It's always nice to feel appreciated and it's not unusual for patients or their families to want to show their gratitude by offering a gift to their doctor. Accepting small tokens such as chocolates or a bottle of wine is unlikely to be a cause for concern. More expensive items, however, including a bequest of money in a will, need to be considered carefully.

"If the bequest is large, it's important to think about how accepting it may be seen by relatives. They may question your relationship with the patient, particularly if the patient was vulnerable. Ask your colleagues' opinion, what would they do in the same situation? Also seek advice from your employer-there may be local policies about accepting gifts which need to be followed-and that of your medical defence organisation. If you decide to accept the money, one option may be to use this for the benefit of other patients-such as for the purchase of medical equipment or something to improve the comfort of a waiting area or relatives' room.

“The GMC states that you mustn't encourage patients to give you money or gifts. Unsolicited gifts can be accepted, however, provided that they don't affect the way you care for patients." 